\title{
Sistema Complemento nas Doenças: Genética e Patogenia ${ }^{*}$
}

\section{The Complement System in Diseases: Genetic and Pathogeny}

\author{
Shirley Ramos da Rosa Utiyama ${ }^{(1)}$, Iara Taborda de Messias Reason ${ }^{(2)}$ e Lorete Maria da Silva Kotze ${ }^{(3)}$
}

\section{RESUMO}

O sistema complemento é parte fundamental da imunidade inata e contribui na remoção de complexos imunes e na ativação de processos inflamatórios. Essas proteínas representam um meio rápido e eficiente de proteção do hospedeiro contra microorganismos invasores. Associações entre complemento e doenças são observadas em situações de deficiência do complemento, anormalidades na regulação do complemento e nas inflamações. Ativação imprópria ou excessiva do complemento pode levar a conseqüências lesivas em virtude da grave destruição tecidual inflamatória. Evidências clínicas e experimentais ressaltam o papel do complemento na patogênese de inúmeras doenças inflamatórias, que incluem não apenas doenças por imune-complexos e auto-imunes, como também falência de órgãos subseqüentes a sepse, traumas múltiplos e queimaduras. O polimorfismo genético tem sido descrito para diversos componentes de membrana, proteínas solúveis de controle e receptores do sistema complemento. Atualmente, o polimorfismo dos componentes do complemento pode ser estudado usualmente, tanto pela pesquisa fenotípica das variantes protéicas (fenotipagem) como pela caracterização genômica do DNA (genotipagem), e tem contribuído para o entendimento da patogênese de diferentes enfermidades. Doenças imunologicamente mediadas estão associadas às variantes alotípicas do complemento, em particular lúpus eritematoso sistêmico, artrite reumatóide, esclerose múltipla, doença celíaca, deficiência de $\operatorname{IgA}$ e $\operatorname{IgG} 4$, entre outras. A presente revisão tem por objetivo dar uma visão dos conhecimentos atuais na área da genética do complemento, bem como da participação desse sistema na patogenia de diferentes doenças.

Palavras-chave: sistema complemento, variabilidade alotípica, inflamação.

\begin{abstract}
The complement system is an important part of the innate immunity and plays an essential role in the clearance of immunecomplexes and in the activation of the inflammatory process. Complement proteins provide rapid and efficient means to protect the host from invasive microorganisms. Associations between complement and diseases are observed in situations of complement deficiency, abnormalities in the regulation of the complement system and inflammation. Inappropriate or excessive activation of the complement can lead to harmful consequences due to severe inflammatory tissue destruction. Clinical and experimental evidences implicate the role of complement in the pathogenesis of numerous inflammatory diseases, which includes not only immune complex and autoimmune disorders, but also organ failure subsequent to sepsis, multiple trauma and burns. Genetic variability has been described for several components, control proteins and receptors of the complement system. Complement protein variability can currently be studied, both by phenotypic assessment of protein variants (phenotyping) and characterization of genomic DNA (genotyping). The genetic variability of complement proteins has provided some light on the pathogenesis of a large group of disorders. Association of different allotypic variants of the complement with immunemediated diseases such as systemic lupus erythematosus, rheumatoid arthritis, insulin-dependent diabetes mellitus, liver cirrhosis, autoimmune hepatitis, multiple sclerosis, celiac disease and IgA/IgG4 deficiency has been described by various authors. The aim of the present review is to provide recent knowledge of the genetics of complement, as well as of the participation of this system in the pathogenesis of different diseases.
\end{abstract}

Keywords: complement system, allotypic variability, inflammation.

\footnotetext{
* Laboratório de Imunopatologia do Hospital de Clínicas da Universidade Federal do Paraná e Serviço de Gastroenterologia e Endoscopia Digestiva, Hospital Universitário Cajurú, Pontifícia Universidade Católica do Paraná. Recebido em 29/03/2004. Aprovado, após revisão, em 16/04/2004

1. Professora adjunta da Disciplina de Estágio Supervisionado de Farmacêutico-Bioquímico e da Disciplina de Imunologia Clínica, do Departamento de Patologia Médica, UFPR.

2. Professora adjunta da Disciplina de Patologia Clínica, Departamento de Patologia Médica, UFPR.

3. Professora adjunta da Disciplina de Gastroenterologia, do Departamento de Clínica Médica da UFPR (aposentada) e do Curso de Medicina da PUC-PR

Endereço para correspondência: Shirley Ramos da Rosa Utiyama. Laboratório de Imunopatologia. Departamento de Patologia Médica, setor de Ciências da Saúde. Rua Padre Camargo, 280, CEP 80060-240, Curitiba, Paraná. E-mail: shirley@ufpr.br
} 


\section{INTRODUÇÃO}

O complemento é parte integrante da resposta imunológica inata do hospedeiro e consiste em um complexo sistema de proteínas plasmáticas e associadas às membranas celulares, reconhecido também como um dos principais mecanismos efetores na defesa contra infecções (Figura 1). Além disso, o complemento desempenha importante papel no processo inflamatório e na remoção de complexos imunes circulantes e células apoptóticas, apresentando além do efeito benéfico para o hospedeiro, uma relevante participação na etiopatogenia de diferentes doenças ${ }^{(1,2,3)}$.

Nas últimas décadas, os conhecimentos adquiridos com relação à genética do complemento levaram a um melhor entendimento de várias situações clínicas graves e do papel desse na susceptibilidade às doenças. Atualmente, existem evidências da variabilidade alotípica para a maioria das proteínas do complemento, destacando-se os componentes $\mathrm{C} 2$, C4 e BF, codificados por genes da região de classe III do complexo principal de histocompatibilidade (MHC), no cromossoma 6 humano ${ }^{(4,5)}$. Alguns alelos desses componentes estão associados a um risco aumentado de doenças auto-imunes e infecciosas, entre outras, e suportam a possibilidade de que essas variantes participariam do mecanismo etiopatogênico dessas doenças, como resultado das propriedades específicas das diferentes variantes $^{(6,7)}$.

\section{O COMPLEMENTO NA PATOGENIA DAS DOENÇAS}

Deficiências hereditárias de quase todos os componentes do complemento e da maior parte das proteínas regulatórias e receptores têm sido detectadas em seres humanos. Essas deficiências, usualmente herdadas de forma autossômica recessiva, são raras e como o complemento não é dosado rotineiramente em indivíduos sadios, torna-se difícil determinar a incidência das mesmas nas diferentes populações. Além disso, apesar das várias atividades biológicas do complemento, muitas vezes as deficiências dos componentes não levam a sintomas clínicos, em função da atuação conjunta das diferentes vias de ativação ${ }^{(9)}$.

Basicamente, têm-se três associações principais entre complemento e doenças: 1) a deficiência associada à suscep-

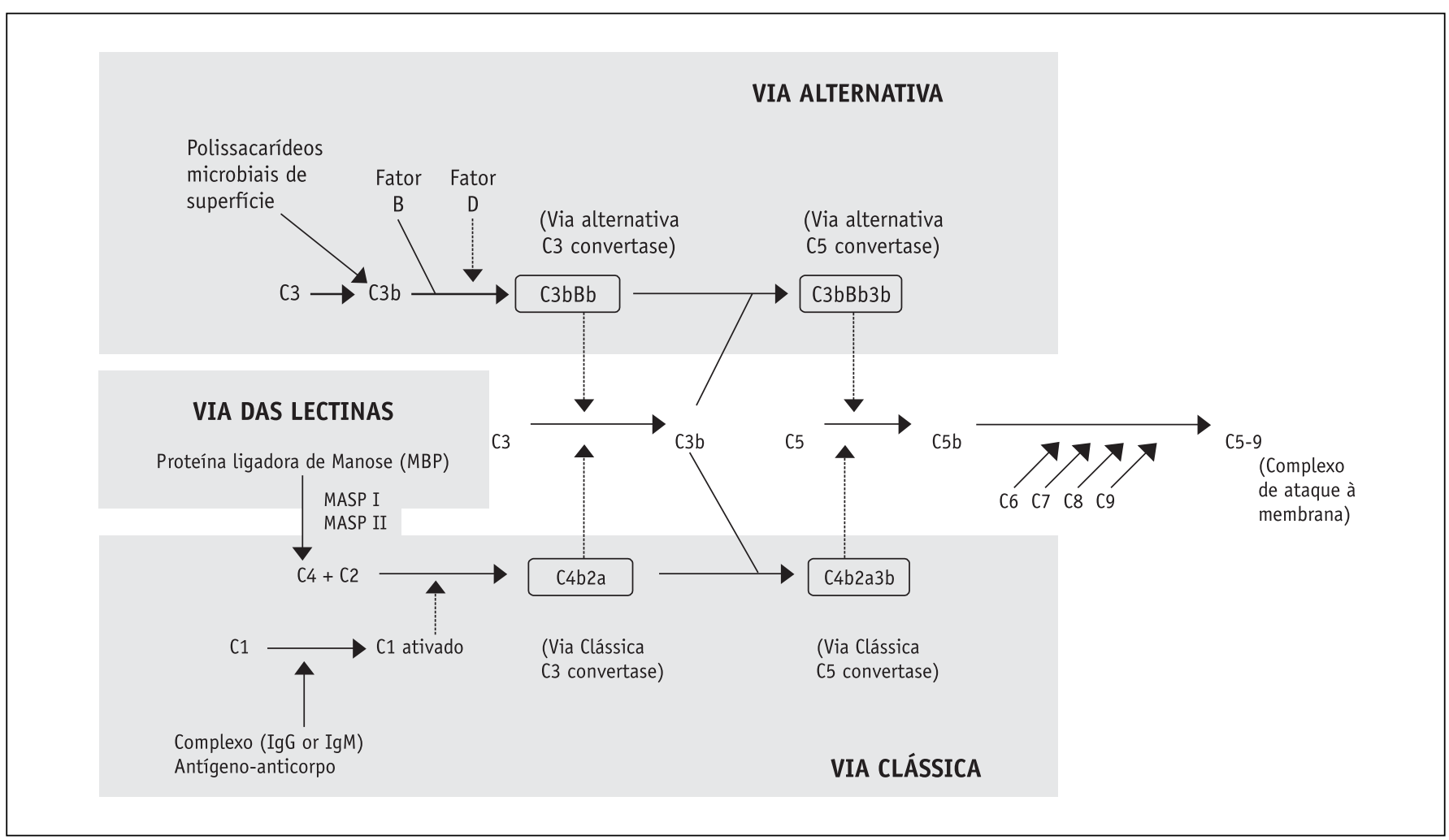

Figura 1 - Vias de ativação do complemento. 
tibilidade a infecções; 2) as conseqüências de anormalidades na regulação do complemento e 3 ) a deficiência associada às doenças inflamatórias ${ }^{(3)}$.

\section{O COMPLEMENTO E AS INFECÇÕES}

As deficiências do complemento relacionadas com o aumento de susceptibilidade a infecções envolvem diversos componentes. A deficiência de C3 compromete as atividades relacionadas com a opsonização e fagocitose, causando uma susceptibilidade maior às infecções por bactérias piogênicas, tais como Haemophilus influenzae e Streptococcus pneumoniae. O mecanismo normal de defesa contra essas bactérias é a opsonização com anticorpos, seguida de ativação do complemento, fagocitose e morte celular. Os fragmentos C3b e iC $3 b$ são as principais opsoninas nesses $\operatorname{casos}^{(10)}$. As deficiências dos componentes terminais do complexo de ataque à membrana (MAC) vão comprometer a atividade lítica e estão relacionadas quase que exclusivamente com infecções por Neisseria meningitidis. Esse fato sugere que a defesa normal contra estas cepas envolve, principalmente, a função bactericida do complemento, com a formação de um canal lítico na bactéria ${ }^{(9,11)}$.

A deficiência da proteína ligante de manose (MBL) também está envolvida com maior susceptibilidade às infecções piogênicas recorrentes, por comprometimento da opsonização ${ }^{(12)}$. Em algumas situações, porém, maiores concentrações da proteína podem, também, estar relacionadas com a gravidade da infecção. Pacientes da Etiópia, com hanseníase virchowiana, apresentaram maior concentração de MBL em relação aos grupos-controles sadios. Sugere-se que a opsonização, por MBL, de organismos intracelulares como as microbactérias possa favorecer a sua entrada nas células ${ }^{(3)}$. Recentemente, foi descrita a deficiência de MASP-2 em infecções de repetição.

Por outro lado ainda, alguns vírus e bactérias intracelulares utilizam-se de moléculas regulatórias e receptores do complemento como um meio de entrar nas células. É o caso do vírus Epstein-Barr com o CR2 de linfócitos B; do vírus da imunodeficiência humana (HIV) com os receptores CR1, CR2 e CR3; o vírus do sarampo com a proteína regulatória MCP e alguns picornavírus com a molécula de DAF, entre outros ${ }^{(3)}$.

\section{COMPROMETIMENTO NA REGULAÇÃO DO} COMPLEMENTO

As deficiências do complemento, gerando anormalidades na regulação, estão envolvidas com diversas proteínas. A deficiência do inibidor de C1, transmitida de forma autossômica dominante, é uma das anormalidades mais comuns e está relacionada com o angioedema hereditário. A doença é recorrente, sendo que traumas ou infecções constituem fatores de ativação do complemento. A ativação de C1 é descontrolada, com geração de $\mathrm{C} 4 \mathrm{~b} 2 \mathrm{a}$ e ativação de cininas. Os fatores que alteram a permeabilidade vascular como $\mathrm{C} 4 \mathrm{a}$, bradicinina, histamina e C2b são os maiores envolvidos no edema e dor, causando grave sintoma quando afeta a mucosa intestinal e podendo causar morte por sufocação, ao levar à obstrução de vias aéreas ${ }^{(13)}$.

Deficiências do fator I e H estão associadas com anormalidade na degradação de C3b, com conseqüente descontrole da clivagem de C3 pela C3 convertase da via alternativa $(\mathrm{C} 3 \mathrm{bBb})$. Isto induz a uma situação de deficiência secundária, por consumo, tanto de $\mathrm{C} 3$ como de $\mathrm{BF}$, levando a infecções por bactérias piogênicas, assim como por meningococos e gonococos ${ }^{(9,13)}$. A deficiência do fator $\mathrm{H}$ também predispõe a glomerulonefrites. Embora não se conheça exatamente o mecanismo, é possível que a ativação contínua de C3, próximo à membrana basal glomerular, leve à deposição de C3b no glomérulo e conseqüente inflamação. $\mathrm{O}$ fator nefrítico de C3 também tem sido associado a glomerulonefrites, principalmente em pacientes com lúpus eritematoso sistêmico. Esse consiste em um auto-anticorpo que se liga e estabiliza a C3 convertase (C3bBb), levando a um consumo descontrolado de C3 e remoção inadequada de complexos imunes, favorecendo o processo inflamatório no glomérulo ${ }^{(10)}$. Deficiências dos fatores P e D também estão associadas com aumento da susceptibilidade a infecções ${ }^{(11)}$.

A hemoglobinúria paroxística noturna é um exemplo de consequiência na falha de regulação do complexo de ataque à membrana (MAC), por comprometimento da expressão do DAF e de CD59 na membrana celular. A causa primária da doença é um defeito genético na síntese de glicosilfosfatidilinositol (GPI), que representa uma âncora para a expressão de mais de 40 proteínas de membrana. A ausência dessas duas proteínas de controle é responsável pela grande sensibilidade do eritrócito à lise pelo complemento, especialmente na condição fisiológica de baixo $\mathrm{pH}$ noturno ${ }^{(11,14)}$.

\section{O COMPLEMENTO E AS DOENÇAS INFLAMATÓRIAS}

O complemento contribui ainda para a inflamação e dano tecidual em doenças neurodegenerativas e auto-imunes, especialmente com manifestações renais e dermatológicas, assim como na injúria isquêmica e reperfusão, ou ainda em situações de choque ${ }^{(14)}$. 
O complemento pode ser ativado nos tecidos por meio dos complexos imunes e de fosfolipídeos e proteínas mitocondriais, expostos após isquemia tecidual e reperfusão. Esses ativam o complemento diretamente, ligando $\mathrm{C} 1 \mathrm{q}$ ou MBL, ou indiretamente pelos anticorpos naturais ou proteína $\mathrm{C}$ reativa, que ativam a via clássica. $\mathrm{O}$ complemento que é ativado nos sítios de injúria tecidual vai causar dano pela deposição do MAC e de ligantes como C4b e C3b que ativam leucócitos com receptores do complemento. As anafilatoxinas C3a e C5a liberadas também contribuem para amplificar a injúria ao promover o influxo e ativação de células inflamatórias. Células e tecidos necróticos não expressam as moléculas regulatórias que previnem a ativação do complemento em tecidos normais ${ }^{(15)}$.

O estado de choque que pode acompanhar a bacteremia por microorganismos Gram-negativos é mediado, em parte, pela ativação de complemento por endotoxinas. As anafilatoxinas liberadas estimulam a agregação intravascular de neutrófilos, levando à formação de êmbolos que se depositam na microvasculatura pulmonar, podendo levar ao edema e choque ${ }^{(16)}$

Sob condições fisiológicas, o complemento contribui efetivamente na eliminação de microorganismos recobertos de anticorpos, promovendo a remoção dos complexos imunes. Entretanto, quando os complexos imunes não são eliminados, o complemento torna-se cronicamente ativado, promovendo a inflamação. Um exemplo disso é na resposta de anticorpos a auto-antígenos que não podem ser carreados do organismo, por estarem limitados a um determinado órgão, no qual a doença se expressa, como na síndrome de Goodpasture e na miastenia gravis. Infecções crônicas, como a hepatite $\mathrm{C}$ e a endocardite bacteriana, também tendem a perpetuar a formação de complexos imunes, com intensa ativação e consumo de complemento ${ }^{(15)}$.

No lúpus eritematoso sistêmico (LES), a ativação de complemento, por complexos imunes que se depositam em múltiplos órgãos, está diretamente ligada à fisiopatogenia da doença. Por outro lado, a deficiência homozigótica hereditária de C1q, C1r, C1s, C4 e C2 está fortemente associada com a susceptibilidade ao LES. O comprometimento na ativação da via clássica, decorrente dessa deficiência, vai refletir, diretamente, na solubilização, bem como na remoção dos complexos. Deficiência de CR1 também compromete a remoção dos complexos, favorecendo a deposição desses em diferentes tecidos e conseqüente inflamação ${ }^{(10,13,14)}$. Outras doenças mediadas por complexos imunes, como artrite reumatóide, glomerulonefrites e vasculites, também apresentam mecanismos semelhantes a estes envolvidos na sua patogenia ${ }^{(11)}$.

Por outro lado, a participação do complemento na eliminação de células apoptóticas dos tecidos é um fator importante na remoção de resíduos celulares, como componentes citoplasmáticos e nucleares parcialmente degradados. Diante de uma deficiência do complemento, principalmente de C1q, há falha na remoção desses resíduos, que pode suscitar uma resposta auto-imune ${ }^{(15)}$.

$\mathrm{Na}$ doença celíaca, a propriedade do glúten de ativar a via alternativa ${ }^{(17)}$, assim como a presença de complexos imunes ativando a via clássica ${ }^{(18)}$ estão diretamente envolvidos no processo inflamatório presente na mucosa intestinal dos pacientes.

Estudos recentes enfatizam ainda o efeito pró-inflamatório da MBL com participação em situações de infarto agudo do miocárdio, doença cardíaca reumática e diabetes mellitus insulino-dependente, entre outras.

\section{GENÉTICA E POLIMORFISMO DO SISTEMA COMPLEMENTO}

Durante as últimas décadas, novos conhecimentos foram adquiridos com relação à genética do complemento, o que levou a um melhor entendimento de várias situações clínicas graves $^{(19)}$. O estudo genético das proteínas do complemento teve início com a descoberta de deficiências do complemento em animais e humanos. Em 1919, Moore descobriu uma linhagem de porquinhos-da-índia com deficiência de complemento. O soro desses animais não mediava a citólise dependente de anticorpo ${ }^{(20)}$.

O primeiro relato de polimorfismo do complemento foi descrito por Alper e Propp ${ }^{(21)}$, para o terceiro componente humano (C3). Desde então, estudos sobre deficiências e polimorfismo, em diferentes espécies, de caráter fenotípico e genotípico têm se acumulado. Tais estudos têm permitido detectar indivíduos deficientes homozigotos e carreadores heterozigotos, em estudos em famílias, e reunir evidências para associações de certos alelos com diferentes doenças ${ }^{(14)}$.

Recentemente, avanços na biologia molecular têm facilitado a caracterização dos alelos do complemento. Tanto a caracterização fenotípica das variantes protéicas (alotipagem) como a caracterização genômica do DNA (genotipagem) são usadas habitualmente ${ }^{(14)}$. Os alelos compreendem as variações de um mesmo gene e diferem 
entre si por pequenas mudanças na seqüência de seus nucleotídeos. Esses ocupam o mesmo locus gênico em cromossomas homólogos e são os responsáveis por uma dada característica. O fenótipo consiste no conjunto de características visíveis ou detectáveis em um indivíduo ou organismo e é determinado pelo seu genótipo e pelas condições ambientais. As diferenças fenotípicas detectadas por métodos imunológicos são denominadas de aloantígenos, enquanto as diferenças por carga e/ou peso molecular, detectadas por métodos eletroforéticos, são denominadas variantes eletroforéticas ou alótipos.

O termo polimorfismo refere-se à ocorrência simultânea de diferentes genótipos, resultantes da combinação de alelos de um mesmo locus, que podem ou não resultar em diferentes fenótipos. Porém, para que um locus gênico seja considerado polimórfico, o seu alelo mais comum não deve apresentar freqüência populacional superior a $99 \%$, de modo que o outro alelo polimorfo tenha freqüência igual ou maior que $1 \%$. Entretanto, a definição clássica preconiza que o termo se refira ao gene (ou locus gênico) e não a cada alelo individualmente. Os alelos de um gene polimórfico são denominados polimorfos (aqueles com freqüência entre 1\% e 99\%) e idiomorfos (com freqüência inferior a 1\%).

A fenotipagem (alotipagem) dos componentes do complemento pode ser determinada por alterações no peso molecular, mobilidade eletroforética, ponto isoelétrico e atividade funcional das diferentes variantes. A metodologia mais utilizada para sua detecção é a da diferença de cargas elétricas, por meio da eletroforese em gel de agarose sob alta voltagem, que é o método básico para a separação das variantes. O gel específico e o sistema tampão variam para cada componente e anticorpos monoclonais permitem distinguir diferentes alótipos ${ }^{(22,23)}$. A genotipagem é realizada por estudos do polimorfismo de fragmentos de restrição (RFPL) e por reação em cadeia da polimerase (PCR), usando primers específicos, seguido de digestão enzimática e seqüenciamento ${ }^{(14,20)}$.

Atualmente, existem evidências de polimorfismo genético para a maioria dos componentes do complemento, destacando-se os componentes iniciais que fazem parte das C3 convertases ( $\mathrm{C} 4, \mathrm{C} 2, \mathrm{C} 3 \mathrm{e} \mathrm{BF})$, assim como algumas proteínas regulatórias solúveis e de membrana, além dos receptores do complemento ${ }^{(4,20,24)}$.

$\mathrm{O}$ aumento significante da freqüência de determinadas variantes genéticas de $\mathrm{C} 4, \mathrm{C} 2, \mathrm{C} 3$ e $\mathrm{BF}$ em uma série de doenças como lúpus eritematoso sistêmico, hanseníase, esclerose múltipla, glomerulonefrite crônica, diabetes mellitus insulino-dependente, artrite reumatóide e espondilite anquilosante, entre outras, suporta a possibilidade de que estas variantes participariam do mecanismo etiopatogênico dessas doenças, como resultado das propriedades biológicas específicas das diferentes variantes ${ }^{(4,6,7,8,22)}$.

\section{VARIABILIDADE ALOTÍPICA DE C3, C4 E C2 E ASSOCIAÇÃO COM DOENÇAS}

A expressão de C3 é controlada por um gene localizado no cromossoma 19. Em humanos, duas variantes alélicas principais foram identificadas baseado na mobilidade eletroforética dos alótipos. São estas: C ${ }^{*} \mathrm{~S}$ (slow) e C $3^{*} \mathrm{~F}$ (fast), além de mais 20 alelos $\operatorname{raros}^{(25)}$. A variante $\mathrm{C} 3{ }^{*} \mathrm{~S}$ é a mais comum, com uma freqüência de 0,$79 ; 0,95 ; 0,97 \mathrm{e}$ 0,99 em brancos, negros americanos, índios sul-americanos e população asiática, respectivamente ${ }^{(26)}$. $O$ significado biológico desse grande número de variantes ainda não está esclarecido, sendo poucos os relatos de associação do polimorfismo de C3. com outras doenças Alguns estudos mostram aumento da freqüência de $\mathrm{C} 3^{*} \mathrm{~F}$ em pacientes com artrite reumatóide, fibrose cística e em pacientes idosos com arterosclerose ${ }^{(23)}$. A diminuição dessa variante foi descrita em pacientes com esquizofrenia ${ }^{(27)}$. A associação de $\mathrm{C}^{*} \mathrm{~S}$ com nefropatia por IgA, lipodistrofia parcial e cirrose em crianças indianas também foi observada ${ }^{(4)}$.

Os componentes C2, C4 e BF são codificados por genes localizados na região de classe III do MHC, no braço curto do cromossoma 6, e são herdados como uma só unidade, denominada complotipo (Figura 2). Dessas três proteínas, C4 é a mais polimórfica, sendo o único componente do complemento que existe como dois isótipos distintos e, cuja síntese é codificada por dois genes diferentes, C4A e C4B. Pelo menos 40 alelos para cada gene já foram relatados, incluindo os alelos nulos, $\mathrm{C}_{4} \mathrm{~A}^{*} \mathrm{Q} 0$ e $\mathrm{C} 4 \mathrm{~B}^{*} \mathrm{Q} 0$, responsáveis pela ausência da proteína $\mathrm{C} 4 \mathrm{~A}$ e $\mathrm{C} 4 \mathrm{~B}$ no soro $(\mathrm{Q}=\text { quantidade zero })^{(26)}$. Apesar da maior parte dos casos de alelos nulos ser devida à deleção do gene, aproximadamente $40 \%$ deles decorre da não-expressão de genes não alterados $^{(28)}$. Alelos nulos de C4A ou C4B ocorrem com uma freqüência de $10 \%$ a $20 \%$ em diferentes populações ${ }^{(20)}$.

Os dois isótipos de C4 (C4A e C4B) diferem apenas em quatro resíduos de aminoácidos, encontrados na cadeia alfa junto à ligação tioester. Essa diferença confere capacidade funcional distinta aos produtos gênicos; dessa forma, C4A, preferencialmente, forma pontes covalentes com grupos 
amina, enquanto C4B liga-se, mais avidamente, a grupos hidroxila. Assim, enquanto $\mathrm{C} 4 \mathrm{~B}$ apresenta um potencial hemolítico pelo menos quatro vezes maior que $\mathrm{C} 4 \mathrm{~A}$, esse último (C4A) tem maior capacidade de fazer ligações covalentes com antígenos protéicos nos complexos imunes ${ }^{(4,20)}$.

Considerando tais aspectos, aliado à importante participação dos componentes $\mathrm{C} 2$ e C4 na remoção de complexos imunes circulantes, é compreensível a crescente lista de associação de deficiência de $\mathrm{C} 4 \mathrm{~A}$ com doenças como lúpus eritematoso sistêmico (LES), artrite reumatóide, esclerose sistêmica, cirrose biliar primária, poliartrite crônica, leishmaniose visceral, glomerulonefrite crônica, lepra, paracoccidiodomicose, diabetes mellitus insulino-dependente e doença de Chagas, entre outras ${ }^{(20)}$.

Uma freqüência aumentada de $\mathrm{C}_{4} \mathrm{~A}^{*} \mathrm{Q} 0$ e $\mathrm{C} 4 \mathrm{~B}^{*} \mathrm{Q} 0$ foi observada em pacientes com LES e lúpus eritematoso discóide, em relação à população normal. $\mathrm{Na}$ esclerodermia, $\mathrm{C}_{4} \mathrm{~B}^{*} \mathrm{Q} 0$ homozigotos ou heterozigotos foram observados com maior freqüência do que nos grupos-controles normais. Associação de alelos nulos de C4 também foi descrita com herpes gestacional, doença de Takayasu e na hepatite crônica auto-imune ${ }^{(23)}$.

Decorrente de um desequilíbrio de ligação com DR3, foi observado um aumento de $\mathrm{C}_{4} \mathrm{~A}^{*} \mathrm{Q} 0 \mathrm{em}$ pacientes com doença celíaca $(\mathrm{DC})^{(29)}$ e com diabetes mellitus insulinodependente ${ }^{(30)}$. A deficiência de C4B tem sido observada em doenças infecciosas como paracoccidioidomicose ${ }^{(31)}$.

O polimorfismo do componente $\mathrm{C} 2$ em humanos foi descrito, inicialmente, por Alper ${ }^{(32)}$, e é caracterizado por uma variante comum $\left(\mathrm{C} 2^{*} \mathrm{C}\right)$ e apenas alguns raros alótipos. A deficiência de $\mathrm{C} 2$ é a deficiência genética mais comum dentre as proteínas do complemento, sendo freqüentemente associada com LES, em caucasóides ${ }^{(33)}$. Em virtude do polimorfismo limitado de $\mathrm{C} 2$, são poucas as associações de suas variantes com doenças, podendo-se citar a associação do alelo $\mathrm{C} 2 * \mathrm{~B}$ com retinopatia proliferativa, em diabetes mellitus insulino-dependente ${ }^{(34)}$.

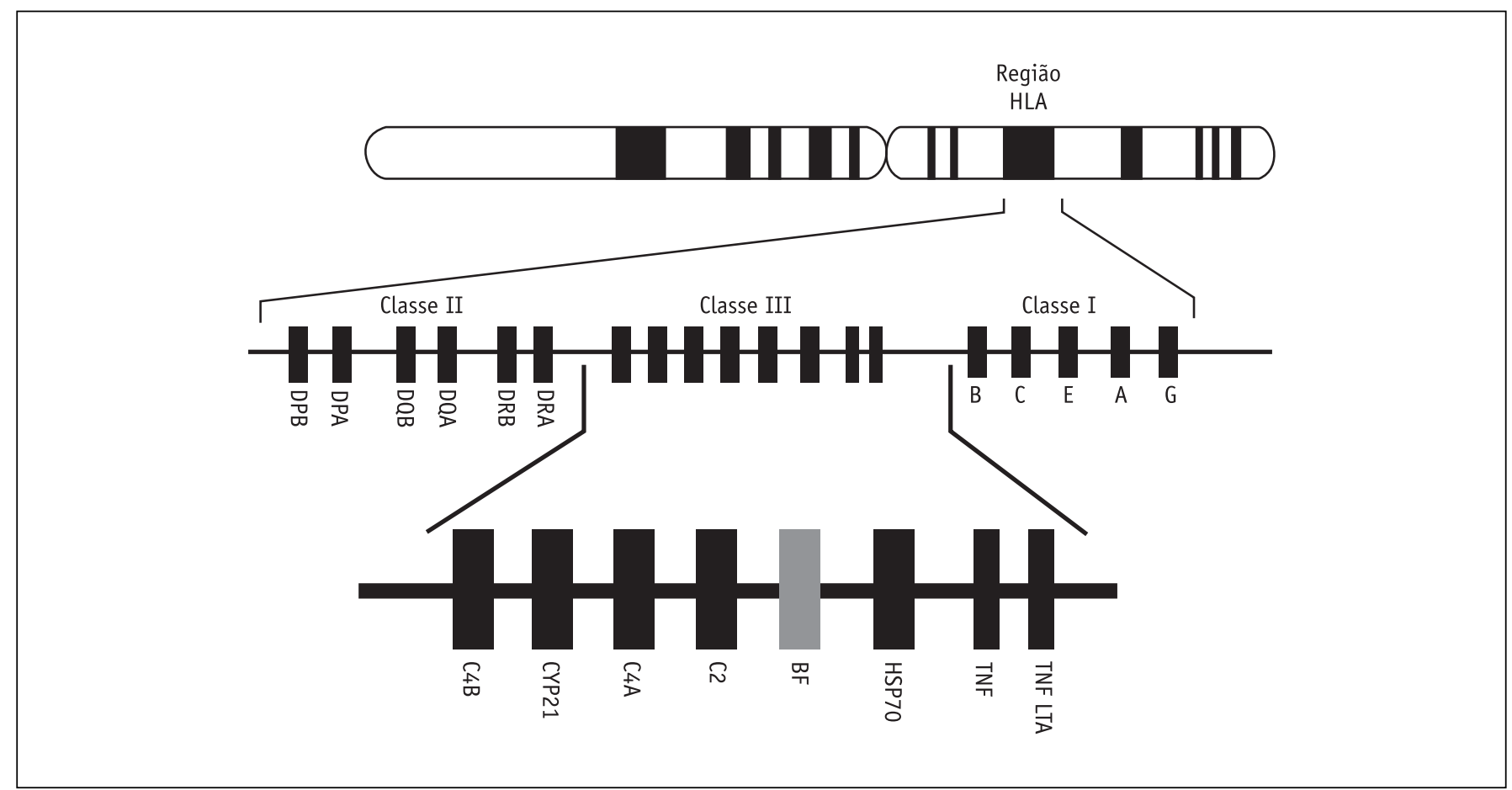

Figura 2 - Cromossoma 6 humano. 


\section{VARIABILIDADE ALOTÍPICA DE BF}

O fator B (BF) foi originalmente descrito como uma glicoproteína II rica em glicina, apresentando dois fragmentos de conversão: GAG (Ba) e GGG $(\mathrm{Bb})$. A molécula BF consiste em uma serina protease (93 KDa), homóloga à C2, com concentração plasmática de $200 \mathrm{mg} / \mathrm{ml}$. O fragmento menor, $\mathrm{Ba}(30-40 \mathrm{KDa})$, constitui a região aminoterminal de $\mathrm{BF}$ e o fragmento $\mathrm{Bb}(60-70 \mathrm{KDa})$ constitui a região carboxiterminal da molécula ${ }^{(35)}$. O polimorfismo de BF foi detectado por eletroforese de alta voltagem em gel de agarose, e subseqüente imunofixação com um anticorpo antifator B humano ${ }^{(36)}$. Foi demonstrada, nessa descrição inicial, a existência de dois alelos comuns, $\mathrm{BF}^{*} \mathrm{~S}$ e $\mathrm{BF}^{*} \mathrm{~F}$, localizados no fragmento $\mathrm{Ba}$, e outros mais raros localizados no fragmento $\mathrm{Bb}$.

Atualmente, o polimorfismo de BF constitui-se em duas variantes principais, $\mathrm{F}$ e $\mathrm{S}$, e duas menos freqüentes, F1 e S07, além de aproximadamente 18 variantes raras. A distância entre o alótipo $\mathrm{S}$ e a variante $\mathrm{F} 1$ foi escolhida como distância referência ${ }^{(37)}$. A atividade hemolítica é máxima para $\mathrm{BF}^{*} \mathrm{~F}$, seguida de $\mathrm{BF}^{*} \mathrm{SF}$ e $\mathrm{BF}^{*} \mathrm{~S}$. A ocorrência de alelos nulos de $\mathrm{BF}\left(\mathrm{BF}^{*} \mathrm{Q} 0\right)$ é extremamente rara, sugerindo que a ativação de $\mathrm{C} 3$ pela via alternativa seja de maior importância biológica do que pela via clássica $^{(23)}$, não se tendo relatos de deficiência homozigótica do mesmo ${ }^{(20)}$.

As freqüências dos alelos comuns e raros de $\mathrm{BF}$ variam nas diferentes populações. De acordo com relatos de vários autores, para o alelo $\mathrm{BF}^{*} \mathrm{~S}$ essa é próxima de 0,71 em brancos, 0,80 em orientais e de 0,28 a 0,44 em negros. Para o alelo $\mathrm{BF}^{*} \mathrm{~F}$ tem-se a freqüência aproximada de 0,28 em brancos, 0,19 em orientais e de 0,51 a 0,65 em negros $^{(36,38,39)}$. Variantes com mobilidade muito rápida ou muito lenta são raras na maioria das populações, com poucas exceções, como em populações que tenham passado por longos períodos de isolamento geográfico e étnico. Um exemplo é a população basca, na qual o alelo BF*F1 atinge uma freqüência de $0,126^{(40)}$. Outros estudos sobre polimorfismo de BF em populações do Japão ${ }^{(41)}$, Grécia ${ }^{(42)}$ e Eslováquia $^{(43)}$ têm sido relatados, com resultados similares aos dos grupos étnicos já citados.

No Brasil, a variabilidade alotípica de C2, BF, C4A e C4B foi estudada por Messias, et al. ${ }^{(44)}$, em um grupo de 225 indivíduos sadios da região Sul do País, incluindo caucasóides, mulatos e negros. Nos caucasóides, a freqüência de distribuição dos alelos de BF foi similar aos relatos de outras populações caucasóides.

\section{ALÓTIPOS DE BF E ASSOCIAÇÃO COM DOENÇAS}

Embora o BF apresente um polimorfismo limitado em comparação com o observado para C4 e para os antígenos de classe I e classe II do MHC, esse representa um marcador de interesse nos estudos de susceptibilidade genética a doenças. Nos últimos anos, várias associações entre o polimorfismo de BF e doenças têm sido descritas ${ }^{(4,5,23)}$.

Diversos estudos têm evidenciado um risco aumentado de desenvolver diabetes mellitus insulino-dependente em indivíduos que apresentem o alelo $\mathrm{BF}^{*} \mathrm{~F} 1$, podendo representar um marcador de susceptibilidade, especialmente em pacientes pediátricos ${ }^{(47,48,49)}$. Os estudos de De Mouzon, et al. ${ }^{(40)}$, no entanto, ressaltam que o haplótipo associado à doença, HLA-B18 C2*C BF*F1 C4A*3 B*Q0, envolvendo um alelo nulo no locus $\mathrm{C} 4 \mathrm{~B}$, não permite afirmar se $\mathrm{BF}^{*} \mathrm{~F} 1$ representa uma associação primária ou secundária com a doença, embora o desequilíbrio de ligação entre HLA-B18 e BF*F1 seja mais forte nos pacientes do que nos grupos-controles. O alelo BF*F1 pode, também, estar envolvido na patogênese da nefropatia membranosa idiopática ${ }^{(50)}$.

A associação dos alelos BF*F1 e BF*S07 com hanseníase virchowiana em negros, foi observada por Mauff; Hitzeroth e Kleeberg ${ }^{(38)}$. Messias, et al. ${ }^{(7)}$, embora tenham detectado associação da deficiência de C4B com a presença de eritema nodoso hansênico, não caracterizaram participação dos alelos de BF como fator de risco no desenvolvimento da hanseníase em pacientes brasileiros.

Os estudos de associação do polimorfismo de BF em pacientes com esclerose múltipla, de diferentes regiões, mostraram diferentes resultados, possivelmente associados às diferenças de distribuição de freqüência de BF entre as próprias populações ${ }^{(51,52)}$.

Destacam-se ainda na literatura outros estudos de associação do polimorfismo de BF com doenças, tais como espondilite anquilosante ${ }^{(53)}$, artrite reumatóide ${ }^{(8,54)}$, pênfigo e penfigóide bolhoso ${ }^{(55)}$, paracoccidioidomicose $\mathrm{e}^{(31)}$, esquizofrenia $^{(27)}$ e glomerulonefrite ${ }^{(56)}$. 
São raros os relatos de associação entre o polimorfismo de BF e a doença celíaca. Destacam-se, entre esses, os achados de Alper, et al. ${ }^{(57)}$, demonstrando aumento na freqüência dos haplótipos [HLA-B8, DR3, BF*, $\mathrm{C}^{*} \mathrm{C}$, $\left.\mathrm{C}_{4} \mathrm{~A}^{*} \mathrm{Q} 0, \mathrm{C}^{\mathrm{B}} \mathrm{B}^{*} 1\right]$ e [HLA-B44, DR 7, BF*F, C2* C, C4A*3, $\left.\mathrm{C}_{4} \mathrm{~B}^{*} 1\right]$ em pacientes celíacos caucasóides, bem como os resultados obtidos por Mannion, et al. ${ }^{(58)} \mathrm{com}$ aumento do haplótipo [HLA-B8, DR3, DQW2, BF*S, $\mathrm{C}_{4} \mathrm{~A}^{*} \mathrm{Q} 0$ e $\left.\mathrm{C}_{4} \mathrm{~B}^{*} 1\right]$ em pacientes irlandeses. Estudos com pacientes italianos caracterizaram aumento significativo na freqüência do alelo $\mathrm{BF}^{*} \mathrm{~F} 1$, em relação a população normal, e uma associação de BF*F1 com Dw3 e de BF*F com Dw $7^{(59)}$. Nenhum desses estudos realizou uma análise de associação entre o polimorfismo de BF e a gravidade da doença.

A Tabela 1 mostra a relação de alelos de BF, C2, C3 e C4 associados a diferentes doenças.

\section{CONSIDERAÇÕES FINAIS}

Todos os aspectos recém-colocados deixam evidente a importante participação do sistema complemento na etiopatogenia de diferentes doenças.

Estudos recentes vislumbram um papel de destaque da imunoterapia de bloqueio de ativação do complemento como forma de tratamento para situações clínicas graves envolvendo o sistema complemento ${ }^{(71)} \mathrm{e}$ ainda de reposição, como na deficiência de MBL, nas infecções em que ocorre associação dessa deficiência.

Por outro lado, o estudo da variabilidade das proteínas do complemento aliado a outros marcadores genéticos tem possibilitado avaliar a susceptibilidade genética de diferentes grupos de indivíduos às mais diversas doenças, bem como às suas diferentes formas de expressão, relacionado, ainda, com dados étnicos e geográficos.

\section{REFERÊNCIAS}

1. Porcel JM, Vergani D: El sistema complemento: una fascinante cascata biológica. Med Clin 100: 428-35, 1993.

2. Sim RB, Laich A: Serine proteases of the complement system. Biochem Soc Trans 28: 545-50, 2000.

3. Walport M J: Complement. N Engl J Med 344: 1058-66, 2001(a).

4. Brai M, Accardo P, Bellavia D: Polymorphism of the complement components in human pathology. Ann Ital Med Int 9: 167-72, 1994

5. Crawford K, Alper CA: Genetics of the complement system. Rev Immunogenetics 2: 323-38, 2000.
TABELA 1

Alelos de BF, C2, C3 e C4 associados com doencas

\begin{tabular}{|c|c|c|}
\hline Alelo & Doenças & Referências \\
\hline$B F * S$ & espondilite anquilosante & 53 \\
\hline \multirow[t]{2}{*}{$B F^{*} \mathrm{~F}$} & nefropatia por IgA & 61 \\
\hline & doença de Alzheimer & 62 \\
\hline \multirow[t]{4}{*}{$B F * F 1$} & nefropatia membranosa idiopática & 50 \\
\hline & doença celíaca & 59 \\
\hline & hanseníase virchowiana & 38 \\
\hline & diabetes mellitus insulino-dependente & 49 \\
\hline \multirow[t]{2}{*}{$\mathrm{BF} * \mathrm{~S} 07$} & hanseníase virchowiana & 38 \\
\hline & diabetes mellitus insulino-dependente & 49 \\
\hline \multirow[t]{2}{*}{ BF SF } & doença celíaca & 59 \\
\hline & artrite reumatoide & 8 \\
\hline \multirow[t]{2}{*}{$\mathrm{C} 2 * 00$} & lúpus eritematoso sistêmico & 33 \\
\hline & lúpus eritematoso sistêmico & 60 \\
\hline $\mathrm{C} 2{ }^{*} \mathrm{~B}$ & retinopatia proliferativa em diabete & 34 \\
\hline \multirow[t]{4}{*}{$\mathrm{C} 3{ }^{*} \mathrm{~F}$} & nefropatia por IgA & 61 \\
\hline & esquizofrenia & 27 \\
\hline & vasculite sistêmica & 63 \\
\hline & osteoartrite e hipertensão em enxaqueca & 64 \\
\hline \multirow[t]{7}{*}{$C 4 A * 00$} & doença celíaca & 29 \\
\hline & diabetes mellitus insulino-dependente & 30 \\
\hline & hepatite auto-imune & 65 \\
\hline & hepatite auto-imune & 66 \\
\hline & lúpus eritematoso & 67 \\
\hline & sistêmicoesclerose múltipla & 68 \\
\hline & doença de Alzheimer & 62 \\
\hline $\mathrm{C} 4 \mathrm{~A} * 2$ & doença de Takaiasu & 69 \\
\hline \multirow[t]{4}{*}{$C 4 B * 00$} & lúpus eritematoso sistêmico & 6 \\
\hline & paracoccidioidomicose & 31 \\
\hline & hanseníase virchowianalúpus & 7 \\
\hline & eritematoso sistêmico & 70 \\
\hline
\end{tabular}

6. Fielder AH, Walport MJ, Batchelor JR, et al: Family study of the major histocompatibility complex in patients with Systemic Lupus Erythematosus: importance of null alleles of C4A and C4B in determining disease susceptibility. Br Med J 268: 425-8, 1983.

7. Messias IJ, Santamaria J, Brenden M, Reis A, Mauff G: Association of C4B deficiency with Erythema Nodosum leprosum. Clin Exp Immunol 92: 284-7, 1993.

8. Watzco W, Messias IJ. Associação entre as variantes genéticas de C3, BF, C4A e C4B do Sistema Complemento e Artrite Reumatóide. Rev Bras Reumatol 34: 243-52, 1994. 
9. Rother KO, Rother U: Complement deficiencies. In: Roitt, IM; Delves, PJ. Encyclopedia of Immunology. 2.a ed. London, Academic Press, pp.378-80, 1992.

10. Abbas AK, Lichtman AH, Pober JS. The complement system. In: Cellular and molecular immunology. 3.a ed. Philadelphia, Saunders, 313-38, 1997.

11. Bing DH, Alper CA: Complement in health and disease. In: Colvin RB; Bhan AK; Mccluske RT. Diagnostic Immunopathology. 2.a ed. New York: Raven Press, 85-94, 1995.

12. Super M, Thiel S, Lu J, Levinski RJ, Turner MW: Association of low levels of mannan-binding protein with a common defect of opsonisation. Lancet 2: 1236-9, 1989.

13. Glovsky MM: Aplications of complement determinations in human disease. Ann Allerg 72: 477-790, 1994.

14. Prodinger WH, Würzner R, Erdei A, Dierich MP: Complement. In: Paul, W. Fundamental Immunology. 4.a ed. Philadelfia: Lippincout-Raven, 967-95, 1999.

15. Walport MJ: Complement. N Engl J Med 344: 1140-4, 2001(b).

16. Roitt I, Brostoff J, Male D: Complement. In: Immunology. 4.a ed. London: Mosby, 13.1-13.17, 1996.

17. Unsworth DJ, Würzner R, Brown DL, Lachmann PJ: Extracts of wheat gluten activate complement via the alternative pathway. Clin Exp Immunol 94: 539-43, 1993.

18. Mohammed I, Holborow EJ, Fry L, Thompson BR, Hoffbrand AV, Stewart JS: Multiple immune complexes and hypocomplementaemia in dermatitis herpetifomis and coeliac disease. Lancet 1: 487-90, 1976.

19. Crawford K, Alper CA: Genetics of the complement system. Rev Immunogenetics 2: 323-38, 2000.

20. Rittner C: Complement, genetics. In: Roitt IM; Delves PJ. Encyclopedia of Immunology, 2.a ed. London: Academic Press 382-5, 1992.

21. Alper CA, Propp RP: Genetic of polymorphism of the third component of human complement (C3). J Clin Invest 47: 2181-91, 1968.

22. McLean RH, Winkelstein JA: Genetically determined variation in the complement system: relatioship to disease. J Pediatr 105: 179-88, 1984.

23. Rittner C, Schneider PM: Genetics and polymorphism of the complement components. In: ROTHER K; TILL GO. The complement system. Heidelberg: Springer-Verlag, pp. 80-135, 1988.

24. Rittner C, Schneider PM: Complexity of MHC class III genes and complement polymorphism. Immunol Today 10: 401-3, 1989.

25. Alper CA, Azen CA, Geserich G: Statement on the polymorphism of the third component of complement in man (C3). Vox Sang 27: 18-20, 1973.

26. Lambris JD, Sahu A, Wetsel RA: The chemistry and biology of C3, C4 and C5. In: Volanakis JE; Frank MM. The Human complement system in health and disease. 1.a ed. New York: Marcel Dekker 83-118, 1998.

27. Fananas L, Moral P, Panadero MA, Bertranpetit J: Complement genetic markers in schizophrenia: C3, BF and C6 polymorphisms. Hum Hered 42: 162-7, 1992.

28. Barba G, Rittner C, Schneider PM: Genetics of human complement C4A deficiency: detection of a point mutation leading to nonexpression. J Clin Invest 91: 1681-6, 1993.

29. Rittner C, DeMarchi M, Mollenhauer E, Carbonara A: Celiac disease and $\mathrm{C} 4 \mathrm{~A}^{*} \mathrm{Q} 0$ : an association secondary to HLA DR3. Tissue Antigens 23: 130-4, 1984.
30. Segurado OG, Giles CM, Iglesias-Casarrubios P, et al: C4 Chido 3 and 6 distinguish two diabetogenic haplotypes: HLA B49, SC01, DR4, DQW8 and B8, SC01, DR3, DQW2. Immunobiology, 183: 12-22, 1991.

31. Messias IJT, Reis A, Brenden M, Queiroz-Telles F, Mauff G: Association of MHC class III complement components $\mathrm{C} 2, \mathrm{BF}$ and C4 with Brazilian Paracoccidioidomycosis. Complement Inflamm 8: 288-93, 1991.

32. Alper CA: Inherited strutural polymorphism in human C2: evidence for genetic linkage between C2 and BF. J Exp Med 144: 1111-5, 1976.

33. Fronek Z, Timmerman LA, Alper CA, et al: Major histocompatibility complex genes and susceptibility to systemic lupus erythematosus. Arthritis Rheum 33: 1542-3, 1990.

34. Bertrams J, Mauff G, Baur MP, Rittner $\mathrm{CH}$ : Association of rare genes products of the $\mathrm{C} 2, \mathrm{C} 4, \mathrm{Bf}$ gene cluster with type I diabetes. Immunobiology 157: 203, 1980.

35. Volanakis JE. Overview of the complement system. In: Volanakis Je; Frank MM. The human complement system in health and disease. 1.ed. New York, Marcel Dekker, 9-32, 1998.

36. Alper CA, Boenich T, Watson L: Genetic polymorphism in human glycine- rich-beta-glicoprotein. J Exp Med 135: 68-80, 1972.

37. Geserick G, Abal M, Mauff G, et al: Factor B (BF) nomenclature statement. Complement Inflamm 7: 255-60, 1990.

38. Mauff G, Hitzeroth HW, Kleeberg HH: Complement haplotypes ("complotypes") of Bf, C4 and C2 are associated with lepromatous leprosy in negroid patients. Immunobiology 164: 274, 1983.

39. Tokunaga K, Araki C, Omoto K: Polymorphism of properdin factor $\mathrm{B}$ in japanese. Description of a rare variant and data of association with HLA and C2. Hum Genet 60: 42-5, 1982.

40. De Mouzon A, Ohayon E, Ducos J: BF and C4 markers for insulindependent diabetes in basques. Lancet 2: 1364, 1979.

41. Ameno, S, Nanikawa R: Genetic polymorphism of factor B (Bf) in Okayama Prefecture, Japan. Acta Med Okayama 38: 321-4, 1984.

42. Triantaphyllidis CD, Ad'hiah A, Karkousis J, Papiha SS: Complement polimorphism in Greece. Ann Hum Biol 16: 443-8, 1989.

43. Stanekova D, Starsia Z, Niks M: Genetic polymorphism of factor B of the complement system $(\mathrm{Bf})$ in the Slovak population. Folia Biol (Praha) 36: 236-9, 1990.

44. Messias IJT, Reis A, Almeida PT, Mauff G: Genetic Variability of the MHC Class III Complement Proteins C2, BF, C4A and C4B in Southern Brazil. Exp Clin Immunogenet 4: 192-6, 1994.

45. Teng Ys, Tan SG: Subtyping of properdin factor B (BF) by isoelectrofocusing. Hum Hered 32: 362-6, 1982.

46. Geserick G, Patzelt D: Factor B (BF) subtyping by isoelectring focusing: methods, nomenclatures, genetics and forensic application. Electrophoresis 9: 418-21, 1988.

47. Raum D, Stein R, Alper CA, et al: Genetic marker for insulindependent diabetes mellitus. Lancet 1: 1208-10, 1979.

48. Orren A, Prescott RA: BF*F1 and C22 gene frequencies in patients with insulin dependent diabetes mellitus (IDDM) from three South African populations. Tissue Antigens 22: 385-8, 1983.

49. Allannic H, Fauchet R, Gueguen M, Savath HP, DinhAT, Genetet B. Factor B (Bf) and glyoxalase genes in insulin-dependent diabetes mellitus. Diabete Metab 11: 22-6, 1985.

50. Dyer PA, Clouda PT, Harris R, Mallick NP: Properdin factor B alleles in patients with idiopathic membranous nephropathy. Tissue Antigens 15: 505-7, 1980. 
51. Bertrams J, Grosse-Wilde H, Kuwert EK: Normal distribution of factor $\mathrm{B}(\mathrm{Bf})$ allotypes in multiple sclerosis. J Neuroimmunol 1: 137-40, 1981.

52. Fielder AHL, Batchelor JR, Vakarelis BN, Compston DAS, McDonald WI: Optic neuritis and multiple sclerosis: do factor B alleles influence progression of disease? Lancet 2: 1246-8, 1981.

53. Migone N, Malavasi F, Boschis D, Modena V: Bf polymorphism and ankylosing spondilitis. Lancet 2: 163, 1978.

54. Lanchbury JS, Pal B, Papiha SS: Bf and C3 polymorphism in rheumatoid arthritis. Hum Hered 37: 144-9, 1987.

55. Nishimukai H, Shiraishi S, Shirakata Y, Sayama K, Shinomiya Y, Miki Y: Complement allotypes in Japanese patients with pemphigus and bullous pemphigoid. Dermatologica 182: 164-7, 1991.

56. Welch TR, Frenzke M: Glomerulonephritis associated with deficiencies and polymorphisms of complement components encoded in the class III region of the MHC. Front Biosci 6: 898-903, 2001.

57. Alper CA, Fleischnick E, Awdeh Z, Katz AJ, Yunis EJ: Extended major histocompatibility complex haplotypes in patients with glutensensitive enteropathy. J Clin Invest 79: 251-6, 1987.

58. Mannion A, Stevens FM, McCarthy CF, Grimes-O'Cearbhaill H, Killeen AA. Extended major histocompatibility complex haplotypes in coeliac patients in the west of Ireland. Am J Med Genet 45: 373-7, 1993.

59. Malavasi F, De Marchi M, Borelli I, et al: Properdin factor B and glioxalase 1 polymorphism in celiac disease. N Engl J Med 303: 530-1, 1980.

60. Lipsker, DM, Schreckenberg-Gilliot C, Uring-Lambert B, et al: Lupus erythematosus associated with genetically determined deficiency of the second component of the complement. Arch Dermatol 136: 1508-14, 2000.
61. Rambausek M, Van Den Wall Bake AW, Schumacher-Ach R, et al: Genetic polymorphism of C3 and Bf in IgA nephropathy. Nephrol Dial Transplant 2: 208-11, 1987.

62. Nemeth A, Urbanics K, Tariska $P$, et al: Molecular genetic markers of Alzheimer dementia. Orv Hetil 136: 1931-5, 1995.

63. Finn Je, Zhang L, Agrawal S, Jayne DR, Oliveira DB, Mathieson PW: Molecular analysis of C3 allotypes in patients with systemic vasculitis. Nephrol Dial Transplant 9: 1564-7, 1994.

64. Peroutka SJ, Price SC, Jones KW: The comorbid association of migraine with osteoarthritis and hypertension: complement C3F and Berkson's bias. Cephalalgia 17: 23-6, 1997.

65. Scully LP, Toze C, Sengar DP, Goldstein R: Early-onset autoimmune hepatitis is associated with a C4A gene deletion. Gastroenterology 104: 1478-84, 1993.

66. Doherty DG, Underhill JA, Donaldson PT, et al: Polymorphism in the human complement $\mathrm{C} 4$ genes and genetic susceptibility to autoimmune hepatitis. Autoimmunity 18: 243-9, 1994.

67. Hong GH, Kim HY, Takeuchi F, et al: Association of complement C4 and HLA-DR alleles with systemic lupus erythematosus in Koreans. J Rheumatol 21: 442-7, 1994.

68. Franciotta D, Dondi E, Bergamaschi R, et al: HLA complement gene polymorphism in multiple sclerosis. A study on 80 Italian patients. J Neurol 242: 64-8, 1995.

69. Numano F, Namba K, Suzuki K, Matsumoto H: Hereditary factors in Takayasu disease. Polymorphism of human complements. Exp Clin Immunogenet 6: 236-44, 1989.

70. Naves M, Hajeer HA, Teh LS, et al: Complement C4B null allele confers risk for systemic lupus erythematosus in a Spanish population. Eur J Immunogenet 25: 317-20, 1998.

71. Kirschfink M: Controlling the complement system in inflammation. Immunopharmacol 38: 51-62, 1997. 